\title{
Constant-light Injury of Potato: Temporal and Spatial Patterns of Carbon Dioxide Assimilation, Starch Content, Chloroplast Integrity, and Necrotic Lesions
}

\author{
Kent E. Cushman', Theodore W. Tibbitts' ${ }^{2}$ and Thomas D. Sharkey ${ }^{3}$ \\ University of Wisconsin, Madison, WI 53706 \\ Robert R. Wise ${ }^{4}$ \\ Department of Biology and Microbiology, University of Wisconsin, Oshkosh, WI 54901
}

Additional index words. Solanum tuberosum, Solanaceae, controlled environment, photoperiod, stress, senescence, ultrastructure

\begin{abstract}
Expanding leaflets of young 'Kennebec' potato plants (Solanum tuberosum L.) develop visible necrotic spotting after 8 to 9 days of constant light and constant temperature, but little is known about this disorder before the appearance of injury. Whole-leaf autoradiography and iodine staining of terminal leaflets $(5$ to $10 \mathrm{~mm}$ long at the beginning of the constant-light period) showed a normal pattern of $\mathrm{CO}_{2}$ assimilation and starch content over the entire leaflet surface after 5 days of constant light. However, small areas of tissue devoid of $\mathrm{CO}_{2}$ assimilation and starch content became apparent on day 6, and these areas expanded to encompass much of the leaflet's medial and basal regions by day 7. At this stage of leaf development, on day 7, leaflets had attained $50 \%$ of their final leaflet length and ceased importing photosynthates from other leaves. Electron micrographs of chloroplasts from the medial and basal regions of leaflets on day 7 revealed a loss of membrane integrity and a senescence-like appearance. At this time, and within these affected regions, scattered groups of necrotic palisade cells began to appear. These scattered groups soon expanded in size and distribution and became apparent as visible necrotic spots on the upper leaflet surface by day 8 or 9. Leaflets on plants grown under constant light hut alternating temperatures, an environment known to be noninjurious, did not exhibit visible spotting or tissue devoid of starch content. In addition, none of these injury symptoms developed in 'Denali', a potato cultivar tolerant of constant light. Despite its occurrence in expanding leaf tissue, constant-light injury appears to be a senescence-like event that leads to the catastrophic loss of photosynthetic competence, starch content, and chloroplast membrane integrity, producing chlorosis and necrosis of leaves and eventually stunting the plant.
\end{abstract}

Certain plant species develop distinct injury symptoms when grown under constant light in combination with constant temperature. Tomato has been studied extensively (Hillman, 1956; Kristoffersen, 1963), and more recently considerable study has been made of the problem with potato (Cao and Tibbitts, 1991). Injury symptoms appear as brown necrotic spotting of the adaxial leaf surface and as interveinal chlorosis, and the injury leads to stunted plant growth. Previous study has documented that injury develops within 5 to 12 days of the beginning of the constant-light period and develops only on young, expanding leaves at the apex of the plant (Hillman, 1956). No study has been made of leaflets before the appearance of visible injury to determine the specific tissues affected by this disorder.

Studies of $\mathrm{CO}_{2}$ assimilation and starch content before and after the appearance of injury have been conflicting. Bradley and Janes (1985) showed that $\mathrm{CO}_{2}$ assimilation and starch content of young tomato leaves generally increased for the first 6 days of constant light and then, with the onset of injury, $\mathrm{CO}_{2}$ assimilation declined steadily while starch content continued to increase slightly. Cao and Tibbitts (1991) showed that $\mathrm{CO}_{2}$ assimilation and starch content were greatly reduced in potato leaves after the appearance

Received for publication 8 Feb. 1995. Accepted for publication 15 June 1995. This research was supported by the College of Agricultural and Life Sciences, Univ. of Wisconsin, Madison; NASA's Graduate Student Researchers Program grant NGT50956; and NASA grant NCC-2-301. This paper \&presents a portion of the dissertation submitted by K.E.C. in partial fulfillment of requirements for a $\mathrm{PhD}$ in horticulture at the Univ. of Wisconsin. The cost of publishing this paper was defrayed in part by the payment of page charges. Under postal regulations, this paper therefore must be hereby marked advertisement solely to indicate this fact. 'Research associate.

${ }^{2}$ Professor, Dept. of Horticulture; to whom reprints requests should be addressed. ${ }^{3}$ Professor, Dept. of Botany.

${ }^{4}$ Assistant professor. of injury. Neither of these reports evaluated the spatial pattern of metabolic activity in affected leaf tissue.

This paper focuses on temporal and spatial patterns of physiological and anatomical changes occurring in leaf tissue before and during the onset of constant-light injury with the anticipation of gaining useful information about the casual factors of this disorder.

\section{Materials and Methods}

Plant culture. Sterile, 21-day-old, tissue-cultured potato plantlets, propagated from micropropagated stem cuttings, wereplanted into 1.8-liter (15-cm-diameter) pots containing moist media-1 peat : 1 vermiculite $(\mathrm{v} / \mathrm{v})$-and covered with plastic cups for the first 3 days to prevent desiccation and to aid establishment. A cultivar injured by constant light, 'Kennebec', and a cultivar tolerant of constant light, 'Denali', were grown in these studies.

The transplants were maintained in a growth chamber and watered automatically 4 times daily to excess with a complete nutrient solution and adjusted to $\mathrm{pH} 5.0$ to 5.5 with $0.1 \mathrm{M} \mathrm{KOH}$ (Hammer et al., 1978). Lighting was by cool-white fluorescent bulbs at $350 \pm 50 \mu \mathrm{mol} \cdot \mathrm{m}^{-2} \&$ photosynthetic photon flux (PPF) at the top of the plant canopy, measured by a quantum sensor (LI- 190; LI-COR, Lincoln, Neb.). Temperature was $18 \mathrm{C}$ and relative humidity (RH) was $70 \%$ (VPD $0.60 \mathrm{kPa}$ ). Light, temperature, and humidity were recorded every $10 \mathrm{~min}$ by a computer monitoring system to ensure that environmental conditions were achieved, and temperature and humidity were calibrated against weekly thermocouple psychrometer readings. Plants were grown for 10 days' under a 12-h light : 12-h dark photoperiod and then exposed to constant light and constant temperature for the rest of each experiment. In one study, plants were moved to a second chamber after the initial 10-day period and maintained with constant light com- 
bined with daily temperature alternations of $13 \mathrm{C}: 23 \mathrm{C}$ on a 12-h : 12-h cycle. This was done to obtain leaf tissue uninjured by constant light, for alternating temperatures of $8 \mathrm{C}$ or more in magnitude prevent the development of constant-light injury on potato (Tibbitts et al., 1990). This second chamber was maintained with a constant VPD of $0.59 \mathrm{kPa}$ at both temperatures.

Leaflet selection. At the beginning of the constant-light period, one terminal leaflet on each plant, 5 to $10 \mathrm{~mm}$ long and located at the plant apex, was identified and termed the target leaflet. This target leaflet was used for most observations and determinations and was harvested in different studies 4 to 15 days after initiation of constant light.

Light and electron microscopy. Some harvested leaflets were cleared of pigments by boiling in $70 \%$ ethanol for 2 min and gentle shaking at room temperature in $70 \%$ ethanol overnight. Leaflets were then placed and maintained in $70 \%$ lactic acid without sectioning for observation of microscopic necrotic lesions with a Zeiss Auxiophot light microscope. To check for possible artifacts created in the leaf tissue with boiling temperatures, other leaflets were cleared of pigments by placing them directly into $70 \%$ lactic acid at $60 \mathrm{C}$ for 14 days. There were no differences in subsequent observations due to clearing method.

Tissue samples for use under the light and electron microscope were excised from target leaflets after 5, 6, or 7 days of constant light. Strips of tissue, $2 \mathrm{~mm}$ wide, from the apical, medial, and basal regions of these leaflets were excised and immediately submerged into a small volume of ice-cold glutaraldehyde fixative (2\% glutaraldehyde in $10 \mathrm{~mm}$ sodium cacodylate buffer, $\mathrm{pH}$ 7.2). Fixation was allowed to continue for $2 \mathrm{~h}$ in the cold, after which the glutaraldehyde was rinsed out of the tissues with three changes of sodium cacodylate buffer. Blocks of tissue, 1-mm square, were cut from these strips and postfixed in $1 \% \mathrm{OsO}_{4}$ (sodium cacodylate buffer at $\mathrm{pH} 7.4$ ) on ice for $2 \mathrm{~h}$, and dehydrated at room temperature in a graded series of ethyl alcohol solutions, and embedded in Spurr's (1969) resin formulation. Blocks were sectioned, $500 \mathrm{~nm}$ thick, stained with toluidine blue ( $1 \%$ in $1 \%$ sodium borate) on a hot plate for $30 \mathrm{sec}$, and then examined with a Nikon Labophot compound light microscope. Exposures were determined by using a Nikon HFX-II exposure control unit, and images were captured on Kodak Tech Pan film. Thin sections, $60 \pm 10 \mathrm{~nm}$ thick, were also sectioned from these blocks, contrasted with uranium and lead, and then viewed in a Zeiss EM 10CA transmission electron microscope operated at 60 $\mathrm{kV}$. Images were recorded on Kodak type 4489 TEM film.

Stainingfor starch content. Whole leaflets that had been cleared of pigments in ethanol were placed in a solution of iodine potassium-iodide to stain for starch content (O'Brien and McCully, 198 1). Leaflets that had been kept in lactic acid were submerged in $20 \% \mathrm{NH}_{4} \mathrm{OH}$ for about $3 \mathrm{~h}$ and then rinsed in distilled water before being stained with iodine solution.

${ }^{14}$ Carbon dioxide labeling. Leaflets were exposed to ${ }^{14} \mathrm{CO}_{2}$ using a leaf chamber and gas-exchange system described by Loreto and Sharkey (1993). Individual plants were moved from the growth chamber to the laboratory where a single leaflet, still attached to the plant, was allowed to equilibrate for 10 to $60 \mathrm{~min}$ to leaf chamber conditions of $35 \pm 1 \mathrm{~Pa} \mathrm{CO}_{2}, 20 \mathrm{kPa} \mathrm{O}, 0.70 \pm 0.05$ $\mathrm{kPa}$ VPD (70\% RH), $20 \pm 1 \mathrm{C}$, and $400 \pm 50 \mu \mathrm{mol} \cdot \mathrm{m}^{-2} \cdot \mathrm{s}^{-1} \mathrm{PPF}$. The leaflet was then exposed to ${ }^{14} \mathrm{CO}_{2}$ at $35 \pm 1 \mathrm{~Pa} \mathrm{CO}_{2}$, specific activity of $3.7 \mathrm{GBq} / \mathrm{mol}(0.1 \mathrm{Ci} / \mathrm{mol})$, for 3 to $4 \mathrm{~min}$. The chamber was flushed for $2 \mathrm{~min}$, and the leaflet was immediately harvested, frozen in a flattened position with a liquid-nitrogen-cooled aluminum plate, placed against cooled Kodak SB-5 diagnostic film, and placed in a $-80 \mathrm{C}$ freezer for 6 to 7 days. Leaflets were separated from the film and thawed and then prepared for microscopic observation and stained for starch content as described above.

These ${ }^{14} \mathrm{CO}_{2}$-labeling procedures were used with target leaflets from plants maintained for 5, 6, and 7 days under constant light. A minimum of four 'Kennebec' and three 'Denali' target leaflets were used.

Similar ${ }^{14} \mathrm{CO}_{2}$-labeling procedures were used to expose a fully enlarged terminal leaflet at the base of the plant to ${ }^{14} \mathrm{CO}_{2}$ to examine the importation of photoassimilates into target leaflets. A terminal leaflet on a leaf three nodes below the target leaflet was placed in the leaf chamber and exposed to ${ }^{14} \mathrm{CO}_{2}$ for $20 \mathrm{~min}$. The chamber was then flushed with air free of radiolabeled compounds for 20 min. Plants were placed in a greenhouse for 4 to $6 \mathrm{~h}$ of daylight exposure, after which a single target leaflet from each plant was harvested, frozen, and placed against film to produce autoradiographs. These leaflets were then prepared for microscopic observation and stained for starch content as described previously. Autoradiographs of a minimum of three 'Kennebec' and two 'Denali' target leaflets were made in this study for each of the 3 days of investigation.

\section{Results}

Leaflet expansion. Despite the development of injury during the latter half of leaflet expansion, extension and final length of 'Kennebec' target leaflets growing under injurious constant-light conditions were not reduced compared to leaflets growing under noninjurious constant-light conditions (Fig. 1). Leaflets increased in length and width for up to 14 days of constant light, whereupon they reached their final size. Extension of 'Denali' leaflets followed a similar pattern of expansion to that of 'Kennebec' leaflets (data not shown).

Transition from heterotrophic to autotrophic tissue. Temporal and spatial patterns of photoassimilate import into target leaflets, made by feeding ${ }^{14} \mathrm{CO}_{2}$ to a fully expanded lower source leaf, revealed significant changes between 5 and 7 days after the start of constant light. At 5 days of constant light, only the basal region of target leaflets, or about a quarter of the leaflet area, was importing ${ }^{14} \mathrm{C}$-labeled compounds from the source leaf. At 6 days, import was

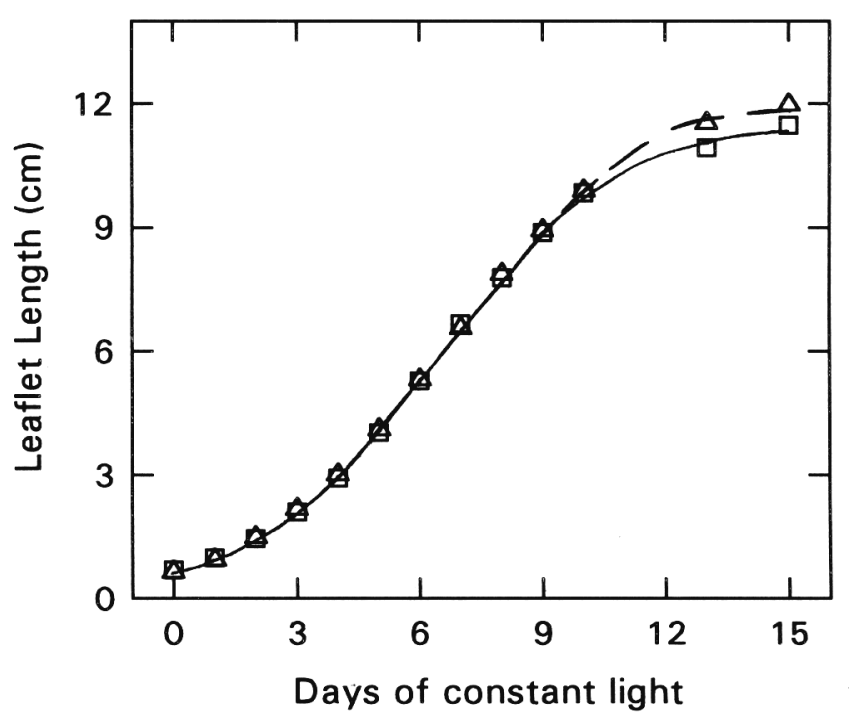

Fig. 1. Extension of terminal leaflets of 'Kennebec' potato under an injurious environment of constant light and constant temperature ( $\square$ ) and a noninjurious environment of constant light and fluctuating temperature $(\Delta)$. Leaflets were 5 to $10 \mathrm{~mm}$ long at the beginning of the constant-light period. Values are means of five leaflets from separate plants. 


\section{Days of Constant Light}

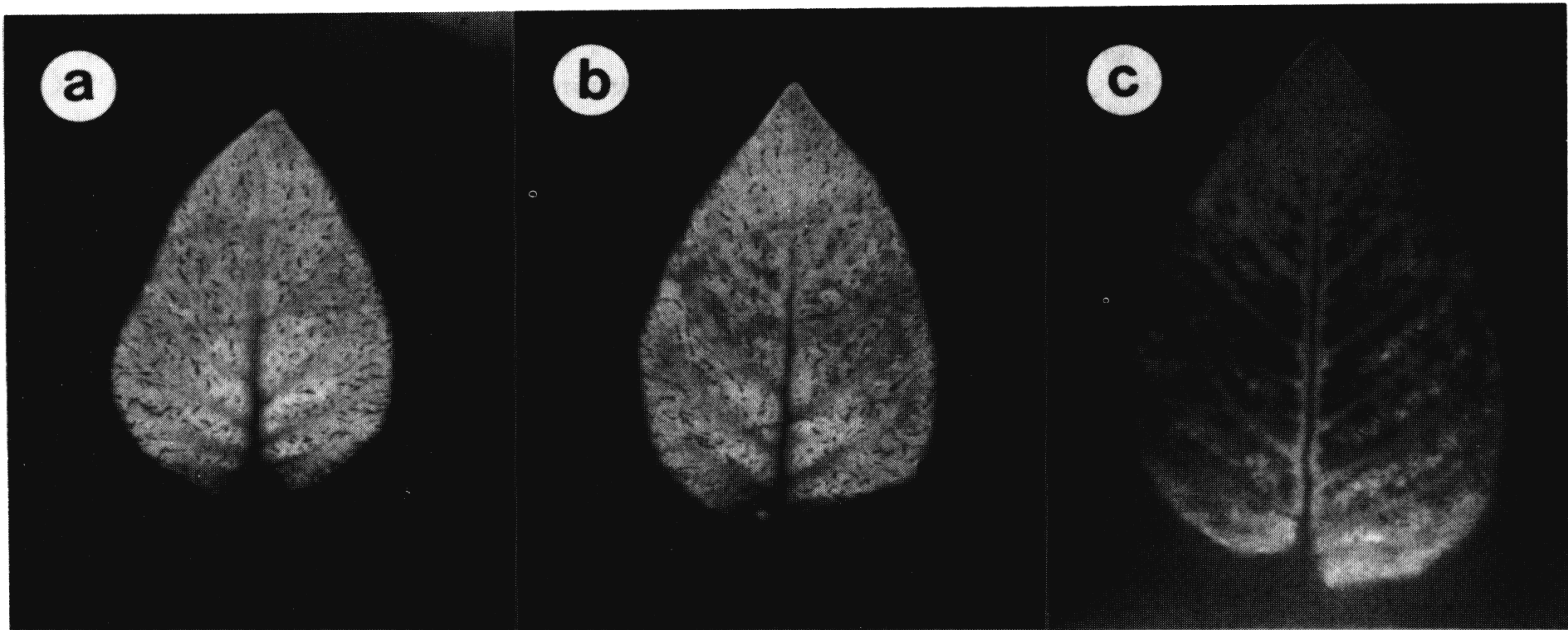

d

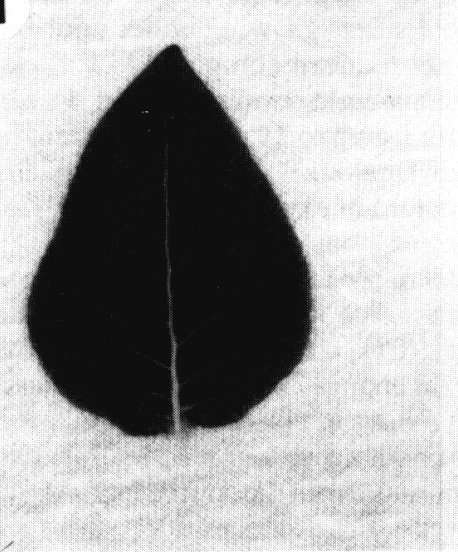

$\mathbf{g}$

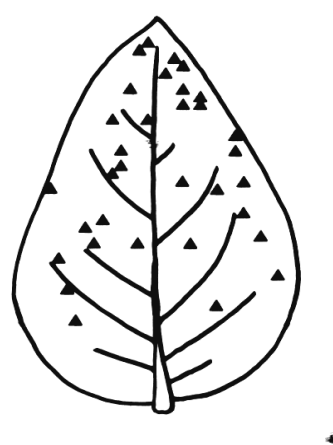

e

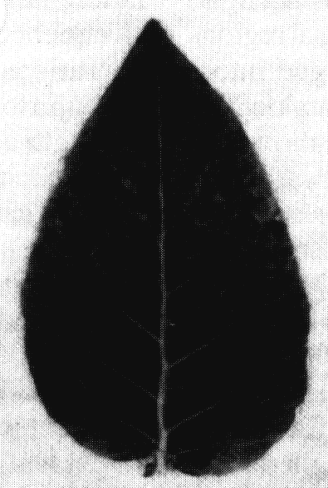

f

i

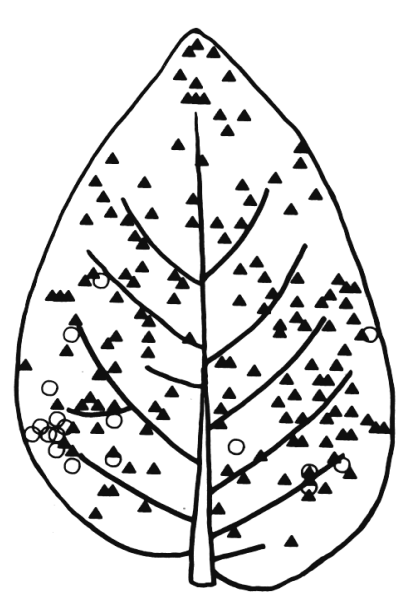

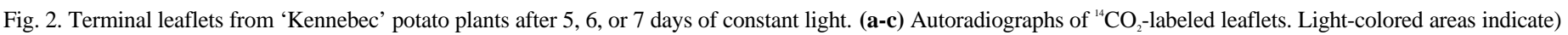

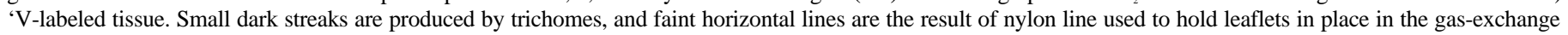

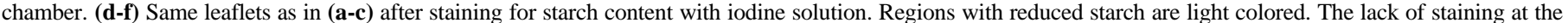

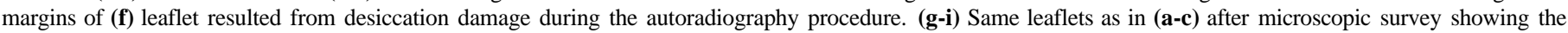
distribution of vascular-associated necrotic lesions (closed triangles) and small groups of necrotic palisade cells (open circles), $\times 0.9$. 
detected only along the basal margin of the leaflet or not at all, and at 7 days, import was not detected in target leaflets. A similar pattern was found in 'Kennebec' and 'Denali' leaflets. Autoradiographs of these leaflets are not shown due to their similarity to other published reports (e.g., Turgeon, 1984).

Examining tissue sections under the light microscope revealed that heterotrophic tissue in the basal region of leaflets on day 5 of constant light exhibited little intercellular air space and contained densely packed cells with small vacuoles. In contrast, autotrophic tissue in the medial region of leaflets on day 5 and the basal region of leaflets on day 6 exhibited greater intercellular air space and contained loosely packed cells with much larger vacuoles (not shown). From these observations, it is apparent that the transition from a tissue of an heterotrophic to an autotrophic function occurred at about the same time as the transition from tissue of densely packed cells to a tissue with significant vacuolar and intercellular air space.
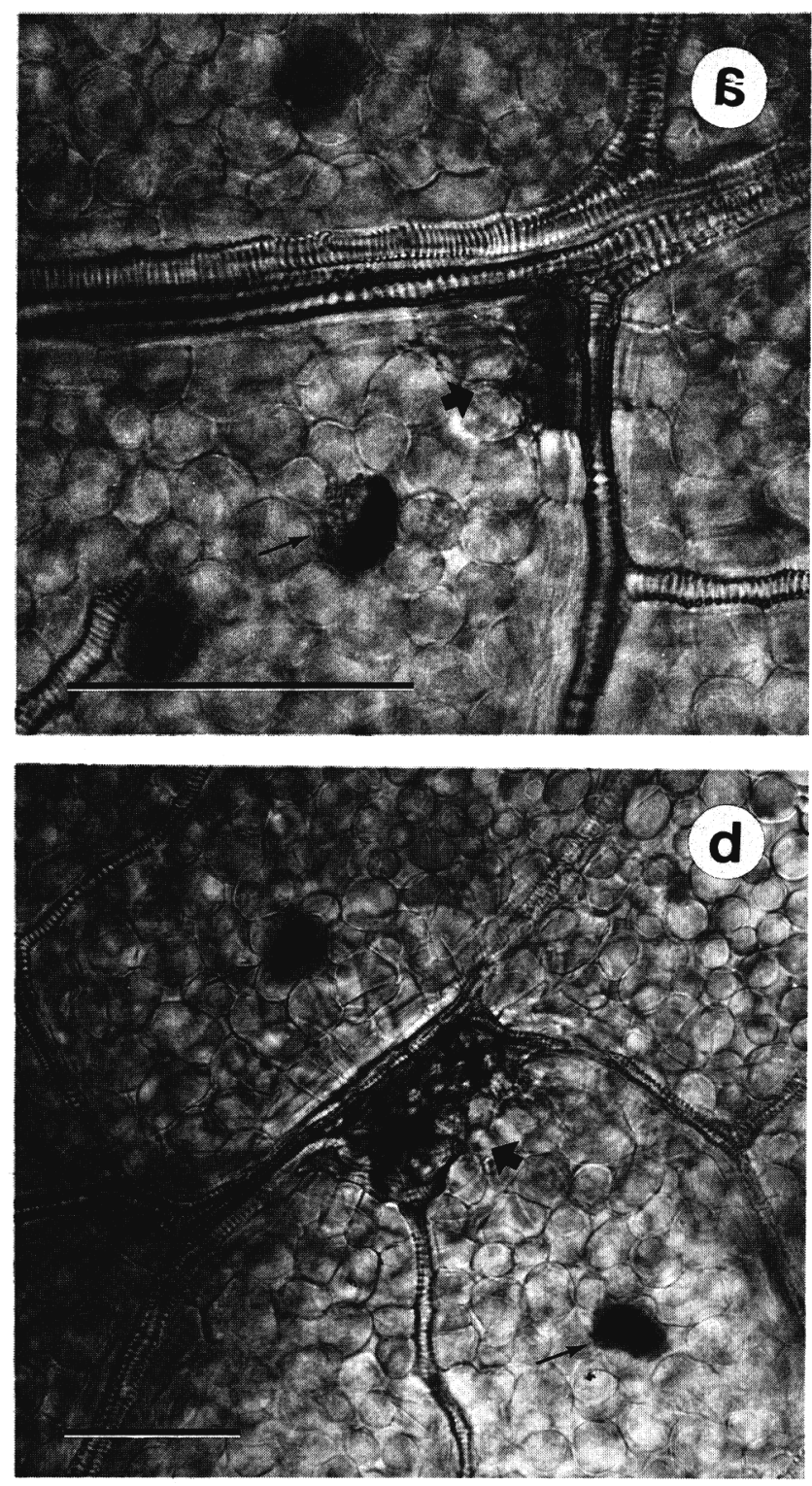

Fig. 3. Vascular-associated necrotic lesions (large arrows) in 'Kennebec' potato leaf tissue consisting of (a) two to (b) many necrotic bundle sheath cells and/or collecting cells adjacent to xylem elements. Sand cells (small arrows) containing calcium oxalate crystals. Scale bars are $0.1 \mathrm{~mm}$.
Carbon dioxide assimilation. A uniform pattern of ${ }^{14} \mathrm{CO}_{2}$ assimilation was evident across the surface of all target leaflets at 5 days of constant light (Fig. 2a). An inhomogeneous pattern began to develop at 6 days in 'Kennebec' leaflets, which revealed small areas of tissue devoid of $\mathrm{CO}_{2}$ assimilation in the medial region of the leaflet (Fig. 2b). This inhomogeneous pattern, or patchiness, expanded basipetally and became much larger in area by day 7 of constant light (Fig. 2c). No evidence of inhomogeneity in $\mathrm{CO}_{2}$ assimilation was detected in 'Denali' leaflets (not shown).

Starch content. In all leaflets examined, a dense and uniform pattern of starch content was evident in target leaflets at 5 days of constant light (Fig. 2d). However, an inhomogeneous pattern began to develop at 6 days in 'Kennebec' leaflets (Fig. 2e), which became much larger in area by 7 days (Fig. 2f). Regions devoid of starch content (Fig. 2 d-f) exhibited an almost identical temporal and spatial pattern of development to regions of reduced $\mathrm{CO}$, assimilation (Fig. $2 \mathrm{a}-\mathrm{c}$ ), indicating that these events occurred simultaneously. No evidence of reduced starch content were detected in 'Denali' leaflets (data not shown).

Necrosis: vascular associated. Groups of necrotic cells were found scattered throughout the apical and medial regions of target leaflets at 5 days of constant light, and their numbers and distribution increased until they were found throughout the entire leaflet on day 7 (Fig. 2 g-i, closed triangles). These necrotic cells consisted of one or more necrotic bundle sheath cells and/or collecting cells and occurred most often at the juncture of two or more minor veins (Fig. $3 \mathrm{a}$ and b). These necrotic cells were closely associated with the vasculature; thus, we have termed these necrotic cells vascularassociated necrotic (VAN) lesions. VAN lesions occurred in the same plane as the vasculature (that is, in the same periclinal cell layer) and, frequently, palisade cells in direct contact with the necrotic bundle sheath and collecting cells were also necrotic or showed evidence of injury where they contacted the necrosis. In general, larger VAN lesions, with or without adjacent necrotic palisade cells, were observed in apical regions of leaflets compared to those in basal regions. The smallest VAN lesions consisted of only one or two necrotic bundle sheath cells and were found in vascular bundles where some xylem elements were still differentiating. Xylem elements were considered to be differentiating if they lacked well-developed secondary wall thickenings. VAN lesions were observed in the apical region of 'Kennebec' leaflets as early as day 4 of constant light. VAN lesions were not observed at any time in leaflets of 'Superior', another cultivar sensitive to constant light that was often included in these experiments, or 'Denali', a tolerant cultivar.

Gas exchange. On day 7 of constant light, $\mathrm{CO}_{2}$ assimilation, as determined by gas-exchange measurements, declined significantly in 'Kennebec' leaflets (Fig. 4a), occurring on the same day that large areas of tissue with greatly reduced ${ }^{14} \mathrm{CO}_{2}$ assimilation and starch content became evident. In contrast, $\mathrm{CO}_{2}$ assimilation in 'Denali' leaflets remained constant over the 3-day period under investigation. Stomatal conductance for water vapor (Fig. 4b) and intercellular $\mathrm{CO}_{2}$ partial pressure (Fig. 4c) did not significantly differ over the 3-day period for either cultivar.

Chloroplast integrity. By day 7 of constant light, chloroplasts located in the medial and basal regions of 'Kennebec' target leaflets were significantly damaged, exhibiting extensive thylakoid dilation and many peripheral vesicles and plastoglobuli (Fig. $5 \mathrm{a}-\mathrm{c})$. Misshapen chloroplasts with pockets of cytoplasm and a granular stroma were seen in many sections (Fig. 5c). Chloroplasts exhibiting injury were detected as early as day 5 of constant light, with the number of affected chloroplasts increasing greatly by day 7. In contrast, most 'Denali' chloroplasts appeared to be unaffected 
by 7 days of constant-light exposure (Fig. 5d). Some 'Denali' chloroplasts exhibited minor development of peripheral vesicles and peripheral reticulum (Fig. 5e), which were clearly attached to the inner membrane of the chloroplast envelope (Fig. 5g). An

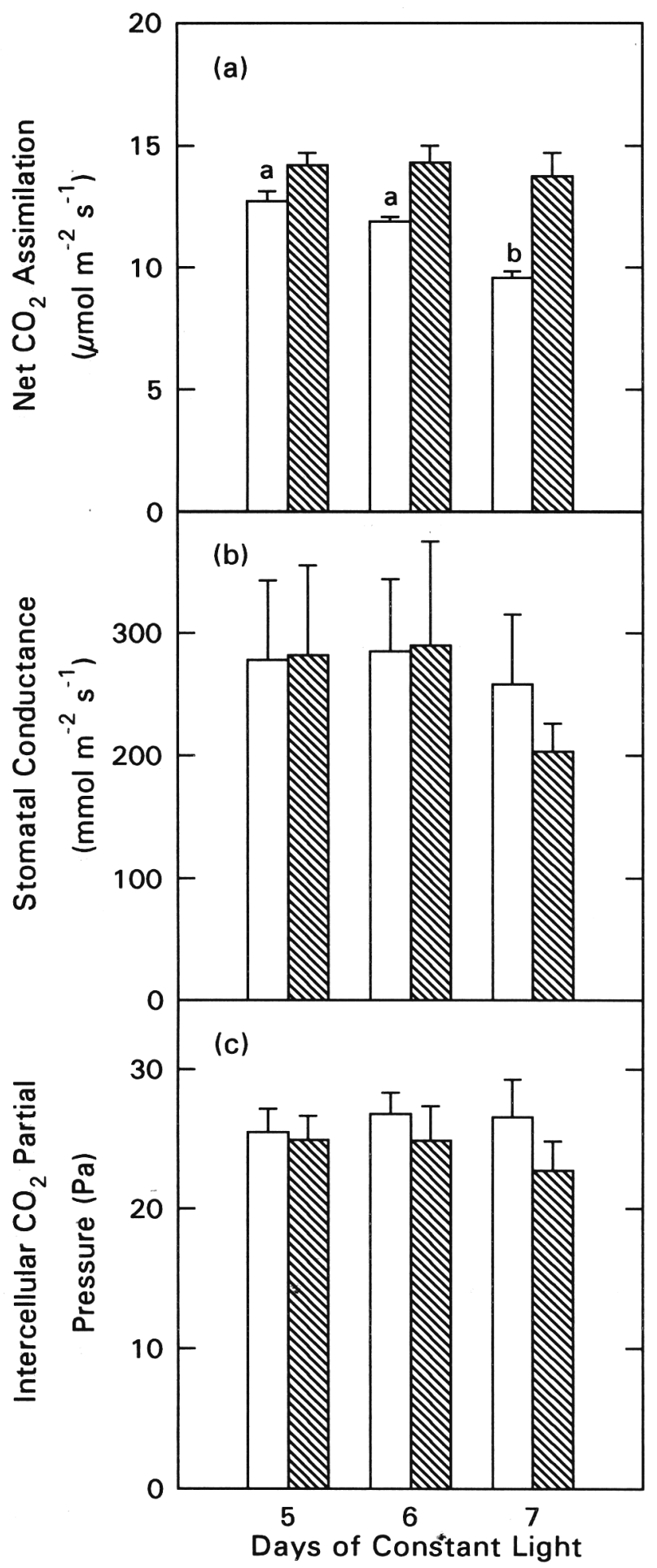

Fig. 4. Gas-exchange determinations made immediately before ${ }^{14} \mathrm{CO}_{2}$-labeling of target leaflets from 'Kennebec' (open bars) and 'Denali' (hatched bars) potatoes. (a) Net $\mathrm{CO}_{2}$ assimilation. (b) Stomatal conductance. (c) Intercellular $\mathrm{CO}_{2}$ partial pressure. Values are means \pm SE from a minimum of four 'Kennebec' and three 'Denali' leaflets. Mean separation for days of constant light by cultivar was by Duncan's multiple range test, $P=0.05$. Bars without letters are nonsignificant. occasional 'Denali' cell had chloroplasts with dilated thylakoids (Fig. 5f). The senescence-like appearance of chloroplasts was the only visible indication of injury to cells or organelles evident during the ultrastructural survey of 'Kennebec' and 'Denali' leaf tissue.

Necrosis: palisade cells. Another form of necrosis, distinct from the VAN lesions described above and consisting solely of groups of palisade cells, was observed under the light microscope in the medial and basal regions of 'Kennebec' target leaflets after 7 days of constant light (Fig. 2i, open circles). These small and scattered groups of necrotic palisade cells were often observed in proximity to major veins, and they eventually expanded into groups large enough to become the visible necrotic spotting characteristic of this injury. By day 8 or 9 of constant light, necrotic spotting was clearly visible on all injured leaflets, and the spotting occurred reproducibly and consistently in a banded pattern across the basal region of the oldest injured leaflets, the medial region of the next older leaflets, and the apical region of the youngest injured leaflets (Fig. 6a). This spatial pattern of necrotic banding was evident not only on terminal leaflets of adjacent leaves, as in Fig. 6 , but also on adjacent leaflets of each compound leaf. Younger leaf tissue, located toward the base of younger leaflets, appeared uninjured at a time when slightly older tissue exhibited injury; however, injury developed in these basal regions upon further exposure to constant light. Older leaf tissue, located toward the apex of older leaflets, was the most resistant to injury and frequently remained uninjured throughout the plant's exposure to constant light. The target leaflets used in these studies first exhibited injury in the medial region of the leaflet, with uninjured tissue located at the apex and base of the leaflet (e.g., Fig. 6, second leaflet from the left). Necrotic palisade cells were never observed in 'Denali' leaflets.

A similar banding pattern on adjacent leaves and leaflets of 'Kennebec' became evident when staining for starch content. Staining revealed large areas of tissue devoid of starch corresponding to the regions of visible injury (Fig. 6b). Regions devoid of starch were larger in area than regions exhibiting necrotic spotting and completely encompassed the necrotic regions. In contrast, 'Denali' showed no evidence of regions devoid of starch at any time during its exposure to constant light (data not shown).

\section{Discussion}

A summary of the temporal pattern of symptom development under constant-light conditions is outlined in Fig. 7. At the beginning of the first day of constant light, target leaflets, 5 to $10 \mathrm{~mm}$ long, were selected for observation. On day 4 or 5 of constant light, VAN lesions were observed in medial and apical regions of target leaflets, and in succeeding days their occurrence progressed basipetally until they were found scattered throughout the entire leaflet. On day 6, an inhomogeneous pattern of ${ }^{14} \mathrm{CO}_{2}$ assimilation and starch content developed in the medial regions of target leaflets, and by day 7 large areas of tissue devoid of ${ }^{14} \mathrm{CO}_{2}$ assimilation and starch content were evident in all but the most apical and basal regions. Chloroplasts in the affected regions that appeared to be uninjured up to this time exhibited thylakoid dilation and the development of peripheral vesicles and plastoglobuli. About this time, on day 6 or 7, leaflets ceased; importation of photoassimilates from other leaves and had reached, $50 \%$ of their final length. On day 7 , microscopic groups of necrotic palisade cells were observed within regions devoid of ${ }^{14} \mathrm{CO}_{2}$ assimilation and starch content. On day 8 or 9 , most of the medial and basal regions were completely devoid of starch content, and 


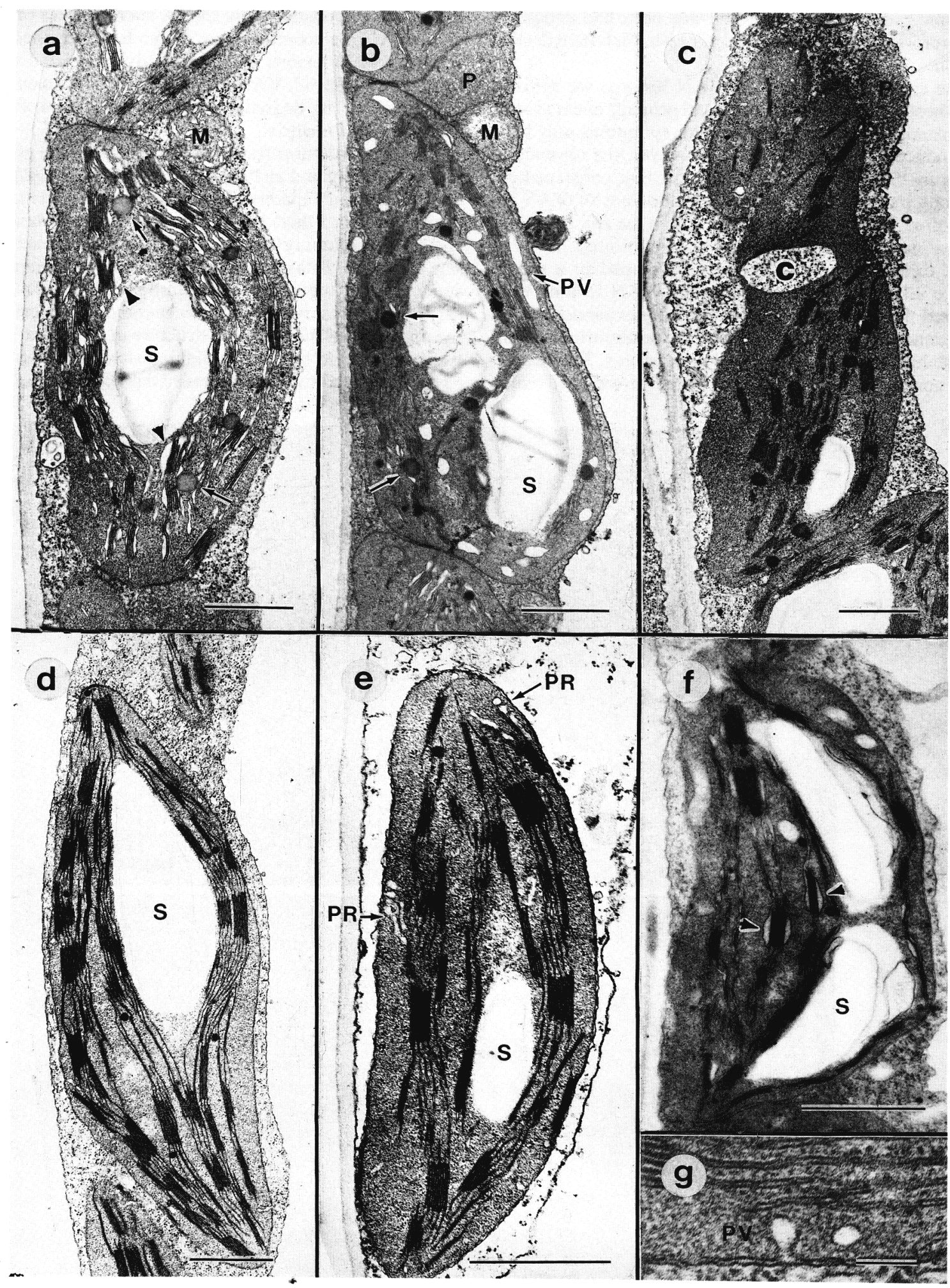

Fig. 5. Ultrastructural characteristics of chloroplasts from the medial region of (a-c) 'Kennebec' and (d-g) 'Denali' potato leaflets after 7 days of constant light. (a) Chloroplast exhibiting severe thylakoid dilation (arrowheads) and plastoglobuli (small arrows). (b) Chloroplast showing extensive development of peripheral vesicles $(\mathrm{PV})$ and plastoglobuli (small arrows). (c) Misshapen chloroplast with granular stroma and a cytoplasmic inclusion (C). (d) Chloroplast showing normal appearing stroma and grana. (e) Chloroplast showing minor development of peripheral reticulum (PR). (f) Chloroplast exhibiting thylakoid dilation (arrowheads). (g) High magnification view of attachment of peripheral vesicle to inner membrane of chloroplast envelope. Starch granule (S), mitochondria (M), peroxisome (P). Scale bar is (a-f) $1.0 \mu \mathrm{m}$ and $(\mathbf{g}) 0.1 \mu \mathrm{m}$. 
the-microscopic groups of necrotic palisade cells had expanded into visible necrotic spotting. By day 14, target leaflets had reached full expansion.

Due to the rapid development of VAN lesions, we initially thought that these lesions were an early and-primary event associated with constant-light injury and that later symptoms may have been stress-induced secondary events. However, the absence of VAN lesions in 'Superior' leaflets indicates that constant-light injury develops independently of the development of VAN lesions. In addition, VAN lesions were present in the apical regions of 'Kennebec' target leaflets, regions that exhibited no other indication of injury; thus, VAN lesions developed in a spatial pattern unlike all other symptoms. Further, VAN lesions were found scattered throughout uninjured, yet fully expanded, target leaflets of 'Kennebec' plants grown under the noninjurious conditions of constant light and alternating temperatures. The leaflets grown under noninjurious constant light, however, did not develop symptoms of constant-light injury, such as areas of starch loss or distinct, visible necrotic spots. Taken together, these results indicate that VAN lesions are not directly associated with constantlight injury; instead, VAN lesions are probably a cultivar-specific expression of the degradative events associated with stressed or senescing leaf material.

Our results demonstrate that chloroplasts were greatly affected, physiologically and anatomically, by constant light. After developing a normal capacity for photosynthesis and starch synthesis during the first 5 days of constant light and constant temperature, and after developing normal chloroplast membrane structure during the same 5 day period, large areas of 'Kennebec' leaflets suddenly lost the ability to assimilate $\mathrm{CO}_{2}$, maintain starch reserves, and preserve chloroplast membrane integrity. Therefore, the ontogeny of function and structure in the leaflet's chloroplasts was not impaired by constant light; instead, function declined catastrophically, and structure degraded markedly, in specific regions of
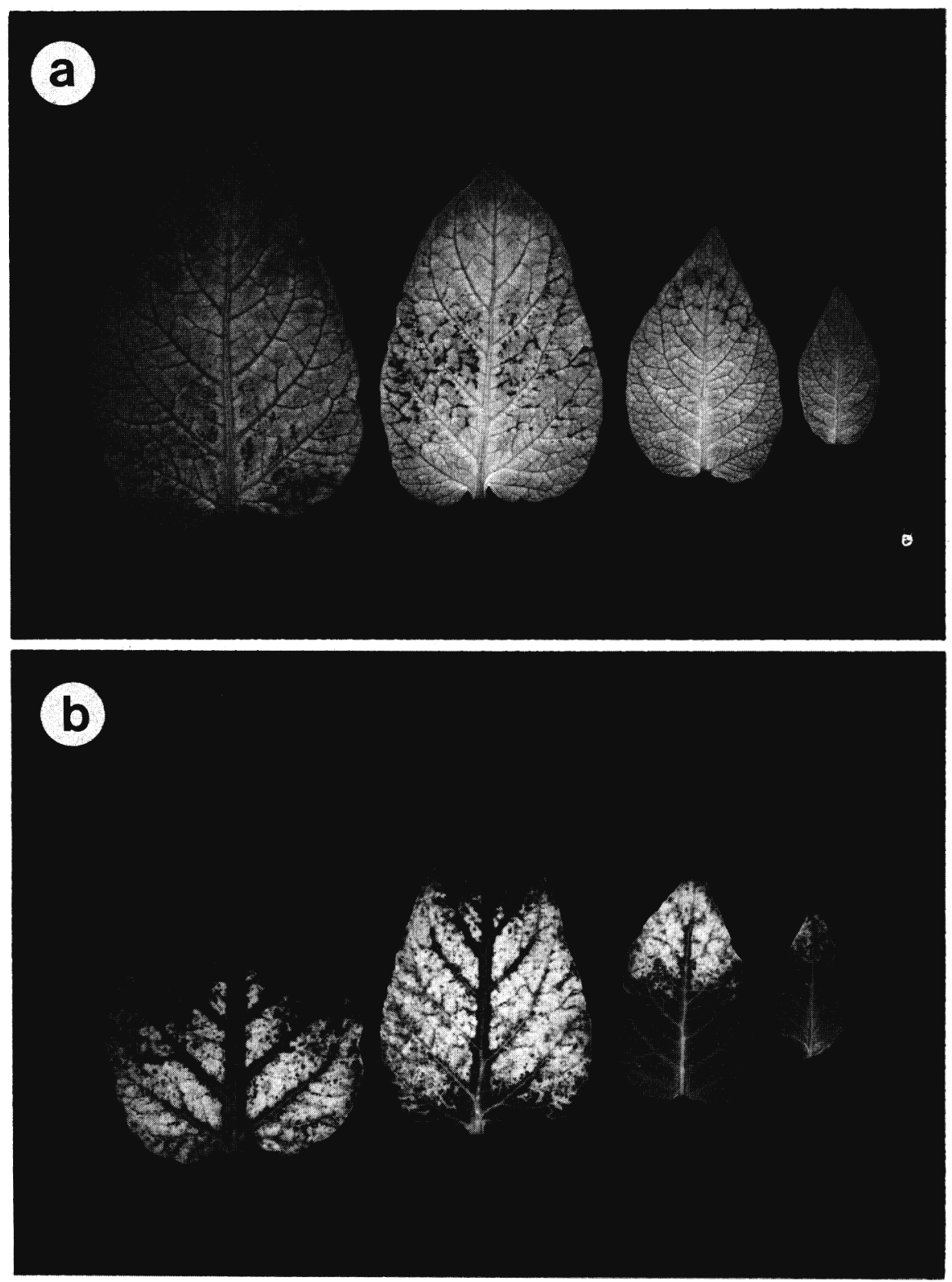

Fig. 6. Terminal leaflets of adjacent leaves from a single plant of 'Kennebec' potato after exposure to 9 days of constant light. The leaflet second from the left was 5 to $10 \mathrm{~mm}$ long at the beginning of the constant-light period. (a) Leaflets cleared of pigments to reveal the pattern of necrotic spotting. (b) Same leaflets as in (a) but stained for starch content with iodine solution. Regions devoid of starch content are light colored, $\times 0.5$. 


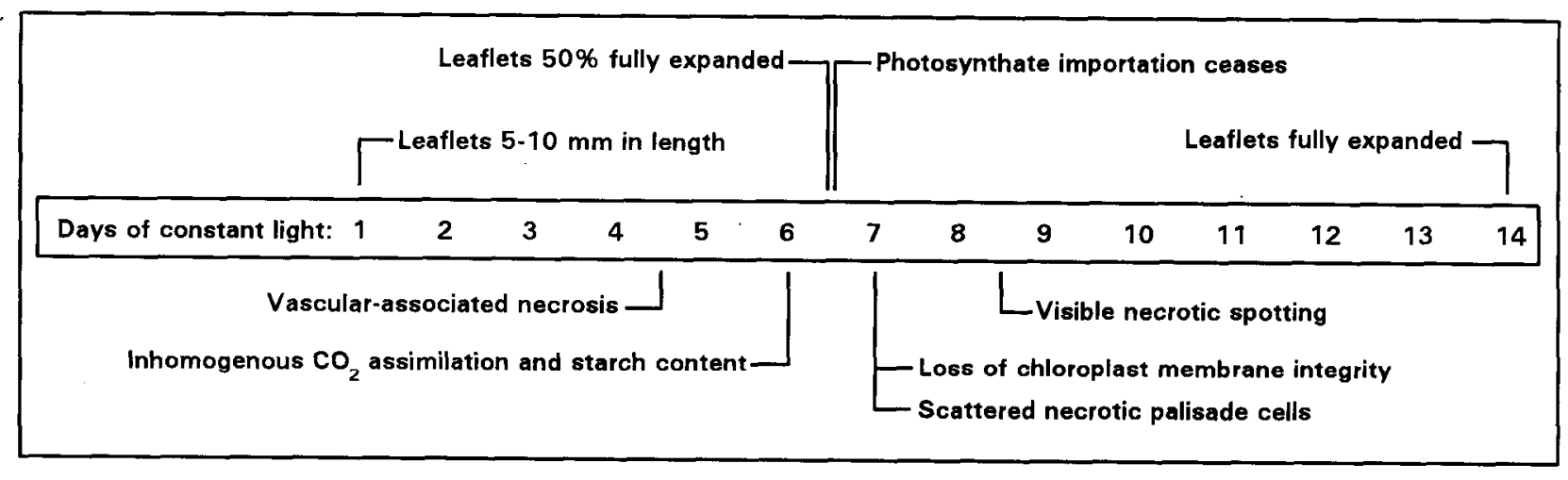

Fig. 7. Summary of leaflet development and initial appearance of constant-light injury symptoms.

the leaflet just before the appearance of visible injury. These results confirm the report that extended periods of constant light greatly reduced $\mathrm{CO}_{2}$ assimilation and starch content in potato (CaO and Tibbitts, 1991). These results also confirm the report that $\mathrm{CO}_{2}$ assimilation decreased markedly in tomato after the first 6 days of constant light, but conflict with the same report that starch content was not simultaneously reduced (Bradley and Janes, 1985).

Our results also show that declines in $\mathrm{CO}_{2}$ assimilation were probably not due to stomata1 limitations, for stomatal conductance was reduced only slightly on day 7 of constant light and the intercellular $\mathrm{CO}_{2}$ partial pressure was not reduced at all during the period under investigation. Similar results of greatly reduced $\mathrm{CO}_{2}$ assimilation but normal stomatal conductance were reported in potato leaves exhibiting visible injury (Cao and Tibbitts, 1991). Therefore, $\mathrm{CO}_{2}$ assimilation probably declined because large areas of the leaflet became photosynthetically incompetent and not because of restricted gas exchange. The loss of $\mathrm{CO}_{2}$ assimilation, starch content, and chloroplast membrane integrity, evident on days 6 and 7, were the earliest events clearly associated with the onset of this injury.

It is interesting to note that the complete loss of chloroplast function throughout large areas of these target leaflets did not interfere with the process of leaf expansion, for leaflets injured by constant light expanded at a similar rate and expanded to a similar size as uninjured leaflets (Fig. 1). This response is similar to the uninterrupted expansion of leaves lacking chlorophyll (Turgeon, 1984).

The temporal and spatial pattern in which constant-light injury symptoms developed revealed that only tissue of a specific physiological age is injured. The banded pattern of injury (Fig. 6) showed that older, fully expanded tissue at the leaflet's apex and younger, densely-packed tissue at the leaflet's base exhibited no loss of function at a time when tissue of an intermediate age, in the medial region of the leaflet, exhibited severe injury. Results from the import study suggest that the boundary between heterotrophic and autotrophic tissue is an important physiological reference point, for injury became apparent only in tissue that had been heterotrophic in function about 1 day before. Therefore, the transition from heterotrophic to autotrophic function may be a general marker for the physiological age at which expanding leaf tissue is most sensitive to the effects of constant light. Soon after this transition, the tissue exhibits a total loss of autotrophy and a subsequent onset of injury symptoms. As a result, injury develops in a banded pattern adjacent to this zone of transition, with injury toward the apex of younger leaflets and toward the base of older leaflets.

The banded pattern of constant-light injury has an interesting corollary to a similar pattern of injury that develops after exposing certain plant species to acute doses of the gaseous oxidants ozone or peroxyacyl nitrates (Hill et al., 1970; Taylor and MacLean, 1970). In addition, ozone has produced necrotic spotting on the upper surface of expanding potato leaves in a banded pattern similar to that reported here (Hooker et al., 1973). Although this corollary is interesting, the specific biochemical mechanism of injury is apparently different between constant-light and ozone injury, for 'Superior' is one of the most tolerant cultivars to ozone exposure (De Vos et al., 1983; Hooker et al., 1973) yet it is one of the most sensitive cultivars to constant-light exposure (unpublished results).

Overall, the development of constant-light injury symptoms in the foliage of sensitive potato cultivars appears to resemble the process of senescence, where major protein and carbohydrate components of the leaf are degraded and their breakdown products are translocated to other locations in the plant (Nooden, 1988; Thimann, 1980). The dilation of chloroplast membranes and the development of peripheral vesicles and plastoglobuli, occurring during the catastrophic decline in $\mathrm{CO}_{2}$ assimilation and starch content, indicate severely stressed or senescent chloroplasts (Harris, 1979; Tevini and Steinmüller, 1985; Wise et al., 1983). Necrotic spotting, developing only within tissue devoid of $\mathrm{CO}_{2}$ assimilation and starch content, visibly indicated that extensive degradative events had already occurred within these regions. It is possible that the symptoms of constant-light injury are similar to other senescence-like events, especially those induced by various kinds of stresses, for it is well known that stress can lead to the rapid degradation of photosynthetic competence, loss of starch content, appearance of necrosis, and senescence of leaf tissue. For example, stress caused by Mn toxicity leads to the development of vascularassociated necrotic lesions, similar to the VAN lesions described here, and to necrotic spotting of the upper leaf surface, chlorosis, and leaf abscission (Foy, 1983; Horst and Marschner, 1978; Lawson and Dienelt, 1991). It is possible that all of the injury symptoms described in this paper are actually secondary events, induced by some unidentified primary event.

In conclusion, we have shown that particular events occur within expanding leaves of susceptible potato cultivars, producing a consistent and reproducible pattern of symptoms before and during the appearance of visible constant-light injury of the foliage. The loss of photosynthetic competence, starch content, and chloroplast membrane integrity are the earliest events associated with this injury. The process and pattern of injury development resemble the degradative events characteristic of senescence, and thus it is concluded these symptoms are probably secondary, senescence-like events that are similar to other stress-induced injuries. 


\section{Literature Cited}

Bradley, F.M. and H.W. Janes. 1985. Carbon partitioning in tomato leaves exposed to continuous light. Acta Hort. 174:293-302.

Cao, W. and T.W. Tibbitts. 1991. Physiological responses in potato plants under continuous irradiation. J. Amer. Soc. Hort. Sci. 116:525-527.

De Vos, N.E., E.J. Pell, R.R., Hill Jr., and R.H. Cole. 1983. Laboratory versus field response of potato genotypes to oxidant stress. Plant Dis. 67: $173-176$.

Foy, C.D. 1983. Thephysiology of plant adaptation tomineral stress. Iowa J. Res. 57:355-391.

Hammer, P.A., T.W. Tibbitts, R.W. Langhans, and J.C. McFarlane. 1978. Base-line growth studies of 'Grand Rapids' lettuce in controlled environments. J. Amer. Soc. Hort. Sci. 103:649-655.

Harris, J.B. 1979. Development of a tubular apparatus in chloroplasts of ageing Cyphomandra leaves. Cytobios 21:151-164.

Hill, A.C., H.E. Heggestad, and S.N. Linzon. 1970. Ozone, p.B1-B22. In: J.S. Jacobson and A.C. Hill (eds.). Recognition of air pollution injury to vegetation: A pictorial atlas. Air Pollution Control Assn., Pittsburgh.

Hillman, W.S. 1956. Injury of tomato plants by continuous light and unfavorable photoperiodic cycles. Amer. J. Bot. 43:89-96.

Hooker, W.J., T.C. Yang, and H.S. Potter. 1973. Air pollution injury of potato in Michigan. Amer. Potato J. 50:151-161.

Horst, W.J. and H. Marschner. 1978. Symptome von mangan-überschuß bei bohnen (Phaseolus vulgaris). Z. Pflanzenemaehr. Bodenkd. 141: 129142.

Kristoffersen, T. 1963. Interactions of photoperiod and temperature in growth and development of young tomato plants (Lycopersicon esculenturn Mill.). Physiol. Plant. Suppl. 1:1-98.
Lawson, R.H. and M.M. Dienelt. 1991. Chrysanthemum foliar necrosis: symptoms, histochemistry, and X-ray analysis of leaf lesions. Phytopathology 81:1071-1078.

Loreto, F. and T. D. Sharkey. 1993. Isoprene emission by plants is affected by transmissible wound signals. Plant Cell Environ. 16:563-570.

Nooden, L.D. 1988. The phenomena of senescence and aging, p. 1-50. In: L.D. Noodén and A.C. Leopold(eds.). Senescence and aging in plants. Academic Press, San Diego.

O'Brien, T.P. and M.E. McCully. 1981. The study of plant structure: principles and selected methods. Termarcarphi, Melbourne.

Spurr, A.R. 1969. A low-viscosity embedding medium for electron microscopy. J. Ultrastruct. Res. 26:31-43.

Taylor, O.C. and D.C. MacLean. 1970. Nitrogen oxides and the peroxyacyl nitrates, p. E1-E14. In: J.S. Jacobson and A.C. Hill (eds.). Recognition of air pollution injury to vegetation: A pictorial atlas. Air Pollution Control Assn., Pittsburgh.

Tevini, M. and D. Steinmüller. 1985. Composition and function of plastoglobuli II. Lipid composition of leaves and plastoglobuli during beech leaf senescence. Planta 163:91-96.

Thimann, K.V. 1980. The senescence of leaves, p. 85-115. In: K.V. Thimann (ed.). Senescence in plants. CRC Press, Boca Raton, Fla.

Tibbitts, T.W., SM. Bennett, and W. Cao. 1990. Control of continuous irradiation injury on potatoes with daily temperature cycling. Plant Physiol. 93:409-411.

Turgeon, R. 1984. Termination of nutrient import and development of vein loading capacity in albino tobacco leaves. Plant Physiol. 76:45-48.

Wise, R.R., J.R. McWilliam, and A.W. Naylor. 1983. A comparative study of low-temperature-induced ultrastructural alterations of three species with differing chilling sensitivities. Plant Cell Environ. 6:525-535. 